\title{
Infantile-Onset Multisystem Autoimmune Disease 1
}

National Cancer Institute

\section{Source}

National Cancer Institute. Infantile-Onset Multisystem Autoimmune Disease 1. NCI

Thesaurus. Code C157123.

An autosomal dominant condition caused by mutation(s) in the STAT3 gene, encoding signal transducer and activator of transcription 3 . It is characterized by variable features along a spectrum of autoimmune disorders affecting multiple organs. Common manifestations may include insulin-dependent diabetes mellitus and autoimmune enteropathy, or celiac disease, and autoimmune hematologic disorders. Other features include short stature and nonspecific dermatitis. 